\title{
Outcomes of Distal Femur Non-Union Following Lateral Locked Plating Treated withan Addition of A Medial Locking Plate and Autogenous Bone Graft
}

\author{
Avtar Singh MS, Rajeev Vohra MS, Babaji Thorat DNB*, Sudhanshu Bansal DB, Anil Naikwadi DNB, and Dharmesh \\ Patel DNB
}

Department of Orthopaedic Surgery, Amandeep Hospital,India

*Corresponding author: Dr. Babaji Thorat, Department of Orthopaedic Surgery, Amandeep Hospital, India

\begin{abstract}
Background: Distal femur non-unions are difficult to treat and can result in chronic pain, significant disability as well as delayed return to preinjury activity functional status. Addition of medial locking plate and autogenous bone grafting adds biomechanical stability, prevents varus collapse and implant failure, and decreases the morbidity associated with non-union. We evaluated results of addition of medial locking plate and bone grafting in aseptic distal femur non-union with stable lateral implant.

Methods: Between 2009 and 2019, we retrospectively reviewed 14 cases of clinically and radiologically established aseptic distal femur non-union treated by single stage procedure involving addition of medial locking plate and autogenous bone grafting. The fractures were classified according to the AO classification system was used for distal femur fractures. Patients were regularly followed-up for a minimum period of 12 months for clinico-radiological signs of union, functional outcome and any complications associated with it.
\end{abstract}

Conclusion:Timely medial locking plate augmentation and bone grafting done is an effective procedure to achieve union and prevent failure of the already present lateral implant in distal femur nonunion

Level of Evidence: Therapeutic Level III.

Keywords: Distal Femur Fracture; Non-Union; Medial Plating; Autogenous Bone Grafting

MeSH Terms: Osteosynthesis, Distal Femur, Non-Union, Plates, Bone Graft

\section{Introduction}

Fractures of the distal third of the femur account for $4 \%$ to $6 \%$ of femur fractures and are a treatment challenge for orthopaedic surgeons despite new fixation options[1]. Fixed angle locking plates have become the most commonly used device for this indication replacing intramedullary nails, blade plates and condylar screws[1]. The biomechanical properties of locked plate designs make them attractive alternatives to conventional plates. Locked screws augment the stability of the construct by eliminating motion at the plate-bone interface providing greater pull-out strength[2,3]. The development of screw torque and plate-bone interface friction is unnecessary with locked plate designs, significantly decreasing the amount of soft tissue dissection required for implantation, preserving the periosteal blood supply[4]. Excellent stability provided by locking plates and minimally invasive biologically friendly insertion should lead to improved healing rates. Unfortunately, clinical experience and some reports in the literature indicate that fracture healing may not be better than that achieved with previous methods of fixation[4-11].Non-union rates ranging from $0 \%$ to $19 \%$ have been reported in the literature[10]. Difficulties with fracture healing in the distal femur may lead to 
poor quality of life, plate bending, plate fracture, plate pull-off and locking screw failure. Fractures treated with lateral locking plates that fail to heal usually maintain alignment and generate less callus, suggesting that callus inhibition because of overly rigid fixation rather than hardware failure is the primary problem[11-32].

We believe the augmentative medial plating and autogenous bone grafting done for healing problems associated with stable locked lateral distal femur plating provides greater stability leading to a successful union and prevent failure of the primary lateral implant. However, to the best of our knowledge, there is less literature available on non-union of distal femur treated with locking medial plate and autogenous bone grafting. We, therefore, sought to determine [1]the preliminary results of the non-union of the distal femur with an in situ stable locking lateral plate after treatment with the addition of a locking medial plate and autogenous bone grafting, and [2] any complications associated with the treatment.

\section{Materials And Methods}

A retrospective clinical evaluation of non-unions of distal femur fractures with an in situ stable lateral locking plate, treated by medial plate augmentation and autogenous bone grafting at was performed in our institute, a National Board of Examinations, India accredited teaching institute. We identified from the hospital data, that between 2009 and 2019, 14 patients of distal femur non-union following locked lateral plating of distal femur identified were treated by augmentative locking medial plate and autogenous bone grafting at a mean of 7.2 months after the primary surgery (range 5 months to 14 months). This study was approved by our institutional review board.In our institution, distal femoral fractures treated by locked lateral plating, not showing expected radiological and clinical signs after three months are kept non-weight bearing and strictly followed for next consecutive three months, for clinical and radiographic signs of progression to healing. Patients with persistent limp, pain and showing no clinical or radiographic signs of progression to healing on plain radiographs or CT (computed tomography) scan, the fracture is considered to be non-united. Inclusion criteria included skeletally mature patient above 18 years of age, absence of infection, a stable lateral locking plate with distal femur nonunion and acceptable alignment after previous/primary surgery. Patients excluded were those with infection, skeletally immature patients. None of the patients had prior treatment for non-union. Two patients reported to our institution with established non-union following surgery elsewhere, and non-union was diagnosed during the routine follow up in 12 patients operated in our institution. Preoperatively, all the patients had disability and pain with twelve of the patients was non-weight-bearing and two were partially weight-bearing on the injured side. The presence of an infected non-union was carefully scrutinized in all patients by clinical evaluation for signs of infection and biochemical markers including complete blood count, erythrocyte sedimentation rate, and C-reactive protein.Five fractures were primarily closed injuries and 9 were open injuries which were, grade I [2], grade II [2], grade III [5]-type a[2], type B [3] according to the Gustilo-Anderson classification system. The surgical procedure was performed by same qualified orthopaedic surgeon involved careful dissection and elevation of medial soft tissues with either medial parapatellar or subvastus approach, packing the non-union site with autogenous bone graft obtained from the posterior iliac crest and fixation using medial locking plate and screws.Information obtained for each patient included patient demographics, injury details (Table 1), type of fracture, soft tissues at the time of original injury (closed vs open), details of prior surgeries, type of non-union (atrophic, oligotrophic, hypertrophic), lateral and medial implant details, duration between the lateral locking plating and the secondary procedure, range of movements at the knee, pain score and ambulatory status before and after the surgery,postoperative complications (Table 2, 3). Our prime outcome measures were union time, weight-bearing ability, range of knee movements. Secondary outcome measures were pain score measured on Visual Analogue Scale (VAS) and postoperative complications.The patients were followed up in the outpatient department (OPD) at monthly intervals for clinical and radiological assessment. The fracture was considered united when the radiographs demonstrated bridging callus across the fracture site along three of the four cortices and the patient could bear full weight without any assisting device and pain. Functionalthe outcome was assessed using LEFS (lower extremity functional scale). The pain score, final weight-bearing ability and range of knee movements were recorded when the fracture was considered to be united. Any complications such as superficial or deep infection, neurovascular complications, mechanical failure of the implant, and absence of bone healing were noted during the follow-up period.

Table 1: Demographics of patients undergoing medial plating and bone grafting for impaired healing after lateral distal femoral locked plating.

\begin{tabular}{|c|c|}
\hline Demographics & Result \\
\hline Number of patients & 14 \\
\hline Average age (range in years) & $46(22-74)$ \\
\hline Sex (Male:Female) & $10: 4$ \\
\hline Primary surgery done at (our institution: outside) & $12: 2$ \\
\hline Injured side (right: left) & $9: 5$ \\
\hline
\end{tabular}




\begin{tabular}{|c|c|}
\hline Injury type (compound: closed) & $9: 5$ \\
\hline $\begin{array}{c}\text { The mean time interval between initial lateral locked plating and addition of medial locking plate with } \\
\text { bone grafting (range in months) }\end{array}$ & $7.2(5-14)$ \\
\hline Follow-up average in years (range in months) & $2.1(12-84)$ \\
\hline Time to union: mean (range in months) & $5(4-7)$ \\
\hline Improvement in Range of motion: mean (range in degrees) & $9.2(10-40)$ \\
\hline Preoperative VAS score: mean (range) & $6.5(5-8)$ \\
\hline Postoperative VAS score: mean (range) & $1.28(0-3)$ \\
\hline
\end{tabular}

Table 2: Demographics, medical history, preoperative ambulatory status and associated injury of patients undergoing medial plating and bone grafting for impaired healing after lateral distal femoral locked plating.

\begin{tabular}{|c|c|c|c|c|c|c|c|c|c|}
\hline Patient & $\begin{array}{c}\text { Age } \\
\text { (years) }\end{array}$ & Sex & $\begin{array}{l}\text { A0 fracture } \\
\text { type }\end{array}$ & $\begin{array}{l}\text { Affected } \\
\text { Side }\end{array}$ & $\begin{array}{l}\text { Simple/ } \\
\text { compound } \\
\text { fracture }\end{array}$ & $\begin{array}{l}\text { Preoperative } \\
\text { weight bearing } \\
\text { ability }\end{array}$ & $\begin{array}{c}\text { Knee Range } \\
\text { of motion (in } \\
\text { degree) }\end{array}$ & Associated injury & Co-morbidities \\
\hline 1 & 26 & Male & $33 \mathrm{~A} 2$ & left & simple & None & 0 to 140 & No & No \\
\hline 2 & 73 & Male & $33 \mathrm{C} 2$ & right & compound & None & 0 to 80 & No & No \\
\hline 3 & 37 & Male & $33 \mathrm{C} 2$ & right & compound & None & 0 to 70 & $\begin{array}{l}\text { Grade } 2 \text { compound } \\
\text { fracture right tibia and } \\
\text { fibula }\end{array}$ & No \\
\hline 4 & 28 & Male & $33 \mathrm{C} 2$ & right & compound & None & 0 to 70 & No & No \\
\hline 5 & 53 & Male & $33 \mathrm{C} 2$ & left & compound & None & 0 to 90 & $\begin{array}{l}\text { Grade 3B compound } \\
\text { fracture left tibia and } \\
\text { fibula }\end{array}$ & No \\
\hline 6 & 54 & Male & $33 \mathrm{C} 2$ & right & compound & None & 10 to 100 & No & No \\
\hline 7 & 29 & Male & $33 \mathrm{C} 2$ & right & compound & None & 0 to 100 & $\begin{array}{l}\text { Grade } 1 \text { compound } \\
\text { fracture right tibia and } \\
\text { fibula with compound } \\
\text { fracture } 2 \text { nd and } 3 \text { rd } \\
\text { right metacarpal }\end{array}$ & No \\
\hline 8 & 45 & Female & $33 \mathrm{C} 3$ & right & compound & None & 10 to 90 & $\begin{array}{l}\text { Grade 3B compound } \\
\text { fracture right upper end } \\
\text { tibia with soft tissue } \\
\text { injury left forearm }\end{array}$ & No \\
\hline 9 & 71 & Female & $33 \mathrm{C} 2$ & right & simple & None & 0 to100 & $\begin{array}{l}\text { Fracture third lumbar } \\
\text { vertebra }\end{array}$ & No \\
\hline 10 & 74 & Female & $33 \mathrm{~A} 2$ & left & simple & Partial with walker & 0 to 100 & No & $\begin{array}{l}\text { Type } 2 \text { diabetes } \\
\text { mellitus }\end{array}$ \\
\hline 11 & 45 & Male & $33 \mathrm{C} 2$ & right & simple & None & 0 to 120 & No & HIV +ve \\
\hline 12 & 22 & Male & $33 \mathrm{~A} 2$ & left & compound & None & 0 to 120 & No & No \\
\hline 13 & 34 & Male & $33 \mathrm{C} 3$ & right & compound & None & 0 to 30 & No & No \\
\hline 14 & 53 & Female & $33 \mathrm{C} 2$ & left & simple & Partial with walker & 0 to 100 & No & Hypothyroidism \\
\hline
\end{tabular}

Table 3: Treatment, implant details, healing and functional status of medial plating and bone grafting for impaired healing after lateral distal femoral locked plating.

\begin{tabular}{|c|c|c|c|c|c|c|c|c|c|c|}
\hline Patient & Previous surgeries & $\begin{array}{c}\text { Type of } \\
\text { lateral } \\
\text { plate }\end{array}$ & $\begin{array}{c}\text { length of } \\
\text { lateral plate } \\
\text { (number of } \\
\text { holes) }\end{array}$ & $\begin{array}{l}\text { Type of } \\
\text { medial } \\
\text { plate }\end{array}$ & $\begin{array}{c}\text { length of } \\
\text { medial plate } \\
\text { (number of } \\
\text { holes) }\end{array}$ & $\begin{array}{c}\text { Time to } \\
\text { union } \\
\text { (months) }\end{array}$ & $\begin{array}{l}\text { Final } \\
\text { range of } \\
\text { motion }\end{array}$ & $\begin{array}{c}\text { improved } \\
\text { range of } \\
\text { motion }\end{array}$ & $\begin{array}{l}\text { Final weight } \\
\text { bearing } \\
\text { ability }\end{array}$ & $\begin{array}{c}\text { Follow-up } \\
\text { (years) }\end{array}$ \\
\hline 1 & ORIF femur & SS DFLP & 10 & SS DTLP & 8 & 4 & $0-140$ & 0 & Full & 1 \\
\hline 2 & $\begin{array}{l}\text { Debridement \& ORIF } \\
\text { femur }\end{array}$ & SS DFLP & 9 & SS PTLP & 7 & 6 & $0-100$ & 20 & Full & 3 \\
\hline 3 & $\begin{array}{c}\text { Debridement, SSG, } \\
\text { ORIF femur } \\
\text { ORIF Tibia }\end{array}$ & SS DFLP & 13 & SS PHILOS & 10 & 6 & $0-80$ & 10 & Full & 1 \\
\hline
\end{tabular}




\begin{tabular}{|c|c|c|c|c|c|c|c|c|c|c|}
\hline 4 & $\begin{array}{l}\text { Debridement \& ORIF } \\
\text { femur }\end{array}$ & SS DFLP & 13 & SS PHILOS & 8 & 5 & $0-110$ & 40 & Full & 5 \\
\hline 5 & $\begin{array}{l}\text { External fixator for } \\
\text { femur fracture then } \\
\text { removal and ORIF }\end{array}$ & SS DFLP & 11 & SS PHILOS & 8 & 5 & 0 to 90 & 0 & Full & 2 \\
\hline 6 & $\begin{array}{l}\text { Debridement \& ORIF } \\
\text { femur }\end{array}$ & SS DFLP & 9 & SS DTLP & 7 & 5 & $10-100$ & 0 & Full & 1 \\
\hline 7 & $\begin{array}{c}\text { Debridement \& ORIF } \\
\text { femur } \\
\text { Debridement, ORIF } \\
\text { and BG tibia } \\
\text { K-wiring metacarpal }\end{array}$ & & & & & & & & & \\
\hline & SS DFLP & 9 & SS DFLP & 5 & 4 & $0-110$ & 10 & Full & 7 & \\
\hline 8 & $\begin{array}{c}\text { Debridement \& ORIF } \\
\text { femur } \\
\text { Debridement, ORIF, } \\
\text { BG, GCN flap \& SSG } \\
\text { Tibia } \\
\text { Debridement \& SSG } \\
\text { forearm }\end{array}$ & & & & & & & & & \\
\hline & SS DFLP & 11 & SS DFLP & 7 & 7 & $10-100$ & 10 & Full & 2.5 & \\
\hline 9 & ORIF & $\begin{array}{l}\text { Titanium } \\
\text { DFLP }\end{array}$ & 13 & SS PHILOS & 8 & 6 & $0-110$ & 10 & Full & 2 \\
\hline 10 & $\begin{array}{l}\text { Total knee } \\
\text { replacement }\end{array}$ & SS DFLP & 13 & SS DTLP & 11 & 4 & $0-100$ & 0 & Full & 1 \\
\hline 11 & ORIF & SS DFLP & 13 & $\begin{array}{l}\text { SS narrow } \\
\text { LCDCP }\end{array}$ & 12 & 5 & $0-120$ & 0 & Full & 1 \\
\hline 12 & $\begin{array}{l}\text { Debridement \& ORIF } \\
\text { femur }\end{array}$ & $\begin{array}{l}\text { Titanium } \\
\text { DFLP }\end{array}$ & 11 & SS DFLP & 7 & 5 & $0-130$ & 10 & Full & 1 \\
\hline 13 & $\begin{array}{l}\text { Debridement \& ORIF } \\
\text { femur }\end{array}$ & SS DFLP & 13 & SS PHILOS & 6 & 5 & $0-40$ & 10 & Full & 1 \\
\hline 14 & ORIF & SS DFLP & 9 & SS DFLP & 7 & 4 & $0-110$ & 10 & Full & 1 \\
\hline
\end{tabular}

\section{Statistical Data Analysis}

Descriptive analysis was carried out by the mean and standard deviation for quantitative variables, $\mathrm{N}$ and proportion for categorical variables. All Quantitative variables were checked for a normal distribution within each category of an explanatory variable by using visual inspection of histograms and normality Q-Q plots. Shapiro-wilk test was also conducted to assess normal distribution. Shapiro-wilk test $\mathrm{p}$-value of $>0.05$ was considered as a normal distribution.For normally distributed Quantitative parameters the mean values were compared between study groups using Independent sample t-test ( 2 groups) and ANOVA test for more than two groups and P-value $<0.05$ was considered statistically significant. IBM SPSS version 20 was used for statistical analysis.

\section{Results}

Out of 12 patients treated in our hospital, 2 patients had a 33A2 fracture, 8 patients had $33 \mathrm{C} 2$ fractures and 2 patients had $33 \mathrm{C} 3$ fracture according to the AO classification. Nine holes to thirteen holes lateral locking plates were used for primary fixation. None of the patients received any bone graft during primary surgery. $1 / 14(7.1 \%)$ patients had a history of diabetes, while there was no history of smoking in any patient.One patient (Figure 1), case 10, a simple fracture treated for a peri-prosthetic fracture following total knee replacement done at our hospital, did not show any signs of healing after 8 months. In 6 compound fractures, wounds could be closed primarily, and three grade $3 \mathrm{~B}$ compound fractures required secondary skin grafting which was done 48 hours after the primary surgery. Four patients with compound injuries had associated compound tibia fractures which were treated by primary nailing in two cases and primary plating in two cases. Repeated debridement and gastrocnemius flap coverage and skin grafting was done for one compound tibia fracture treated with a plate [8].In this study, non-union was confirmed on plain radiographs in six cases, and the combination of CT scan and plain radiographs established the nonunion in 8 cases. In one case, due to the obvious radiolucent line on x-rays at 5 months, the diagnosis of non-union was considered 
and augmentative medial plating and bone grafting was done. All non-unions were oligotrophic in nature. None of the patients had an intra-articular non-union. Persistent pain and the limp were present in all the patients. Twelve patients were not bearing weight, and 2 patients were bearing partial weight with the help of a stick. Visible motion at the non-union site in [13] cases with varus/valgus stressing was observed under fluoroscopy intraoperatively. Medial sub vastus approach was used for the exposure of non-union site in 10 patients with more than 90/100 degree range of knee movements and medial para-patellar approach was used in 4 patients who had limited range of movements of the knee and required release the intra-articular adhesions. All plates used for medial augmentation were made of stainless steel. Autogenous iliac bone graft was added in all cases with the aim to stimulate local osteogenic activity and increase in stability with the addition of medial locking plate. During our follow-up period which was in average 2.1 years (range 12 months to 84 months), the union was achieved in all patients at a mean of 5 months (range 4-7months). Only subtle improvement in the range of motion of the knee (mean 9.2 degrees) was noted. Patients had a good functional outcome with an average LEFS score of 71 (50 to79). One patient [7] developed a deep infection after six years of the surgery and was managed with debridement and removal of both medial as well as lateral implants.

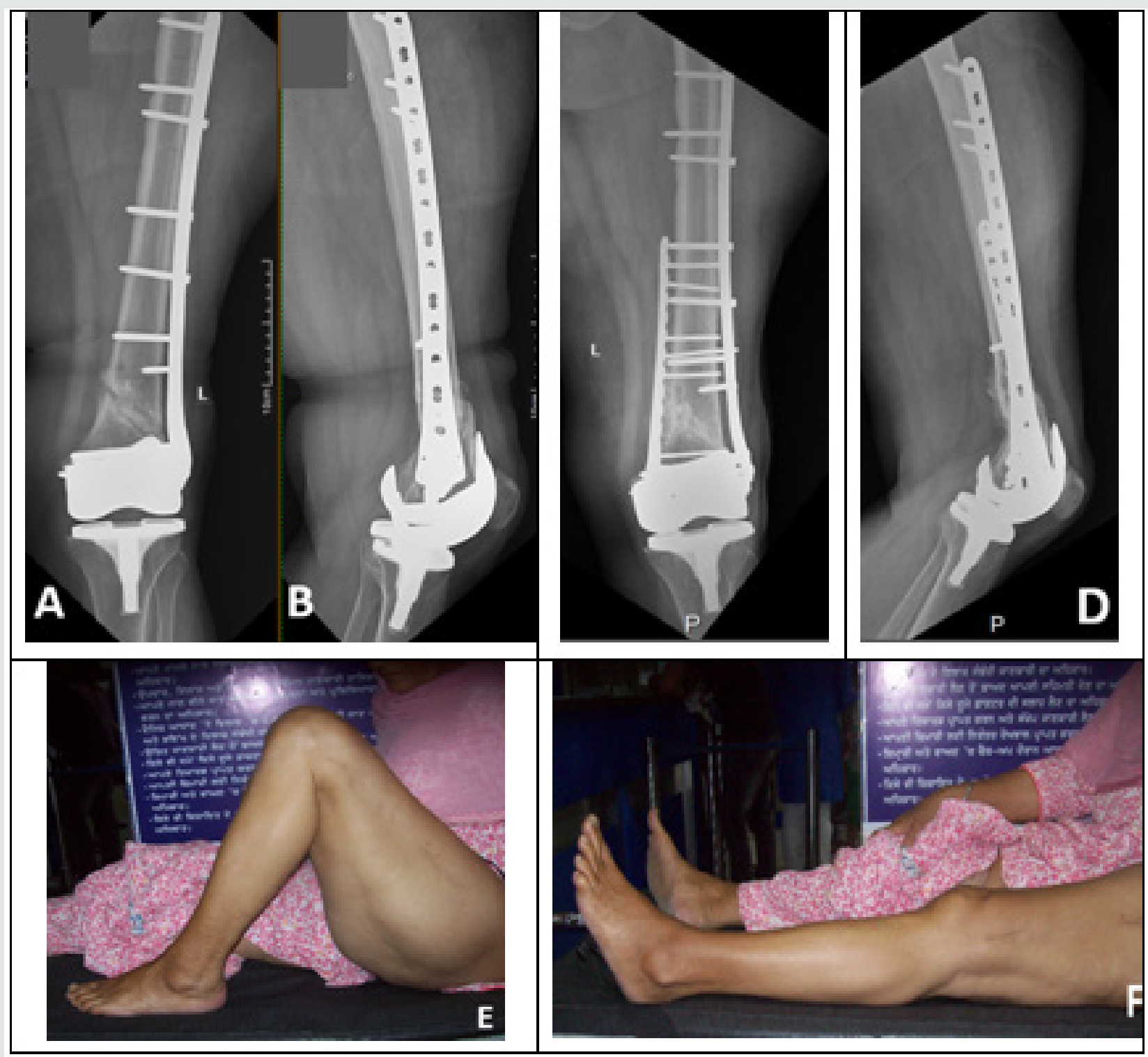

Figure 1A-D: (A and B) anteroposterior and lateral radiographs of a 74-year-old female (Case 10) with established nonunion distal femur after locking lateral plating. (C and D) Final anteroposterior and lateral radiographs showing solid bony union without any shortening or deformities with clinical pictures (E and F). 


\section{Discussion}

Distal femoral fractures represent $4-7 \%$ of all femoral fractures[12,13]. The implants used for the fixation of these fractures include extra-medullary devices like fixed-angle devices (angled blade plate, dynamic condylar screw, and condylar buttress plate), locking plates, and intramedullary devices like retrograde and ante-grade intramedullary nails. Recently locked plate systems are most commonly used for fixation of distal femoral fractures, because of minimally invasive biologically friendly insertion techniques developed to place the plate without excessive soft tissue-stripping and with minimal disruption of the bone blood supply $[1,4]$. Similar to intramedullary nails, these plates are used to span zones of comminution which then heals with an external callus. Biomechanically they have been designed to limit fracture gap strain with physiologic loads and have improved fixation in osteoporotic, cancellous, or comminuted bone [1-14]. As the use of fixed angled locked plates for distal femoral fractures increased, reports of failures came along with reports of clinical successes. When the healing response after lateral locked plating of the distal femur is not fast enough then the implant may fail leading to plate bending, plate fracture, plate pull-off, and locking screw failure [4]. The causes and risk factors for these healing delays remain uncertain. Although patient factors like diabetes mellitus, compound nature of the injury and increased BMI known to impair healing are beyond the control of a surgeon, numerous authors have attempted to identify the technical factors predisposing to failure of lateral locked plate fixation for distal femoral fractures. Ricci et al identified the plate length as a technical factor predisposing to plate failures and recommended longer plates due to their superior fatigue properties for the treatment of these fractures. He also suggested that the severity of trauma and comorbid conditions such as diabetes and obesity are also determinant factors for nonunion[15]. Lujan et al, pointed out that inconsistent and asymmetric formation of periosteal callus following lateral locked distal femoral plating may be attributed to the high stiffness of the construct, which can be improved mildly by increasing the bridging span and can be further decreased by using more flexible titanium plates, as titanium implants are normally twice as flexible as similar-sized stainless steel implants[16]. The use of titanium versus stainless steel plates has been reported to correlate with varying degrees of union rates in various series[11,17,18]. Rodriguez et al, tried to identify construct characteristics like screw density, plate design and material as predictors of non-union after locked lateral plating of the distal femur and found combined plate design and material to have a significant influence on the risk of non-unionLinn, et al[18]. suggested dynamic locked plating to increase the axial motion in metaphyseal bridge plating of distal femur fractures. Dynamic plating was achieved using an over drilling of the near cortex while inserting the proximal screws. They concluded that dynamic plating seems to allow better callus formation without fixation failure[19].
Poly-axial screw plate designs were used in an attempt to improve peri-articular control by the placement of locking screws in a range of insertion angles[20,21]. But the high rate of early mechanical failure with the variable angle distal femoral locking compared to traditional locking plates has been reported and the authors cautioned practising surgeons against the use of this plate for metaphyseal fragmented distal femur fractures[22].

Multiple strategies like increasing plate length and thickness, modifying screw density, use of dynamic locked plating and variable angle locked plating, and use of titanium plates, has been recommended to increase construct strength and stability, and promote healing of distal femoral fractures with locked lateral plates, but still, the healing remains unpredictable[4-22]. Distal femoral non-unions following locked lateral plating can cause persistent pain, limp, loss of ambulatory function, and decreased range of motion at the knee[23,24].In the presence of these alarming signals, the surgeon should suspect healing problems. The radiographs of the previous three months need to be compared to assess the progress of the union, loss of reduction, change of alignment.Out of 14 patients in our series, 12 fractures were primarily fixed with stainless steel lateral locked plates and two with titanium plates. Because of the low cost, stainless steel implants are commonly used in our part of the world and the decreased flexibility of these implants as pointed by different authors[11-18], may have contributed to the impaired healing seen in these patients.Open fractures are often associated with significant stripping of periosteum, damage to bone and soft tissues, and disruption of vascularity[25]. The open nature of the injury has been shown to contribute to the development of nonunion of distal femoral fractures[24]. In our series, there were 9 compound fractures and five patients had Grade III compound injuries. The compound nature of the fracture was a probable factor in the development of non-union in these cases. Out of 9 compound cases, 6 six cases were closed with primary suturing, and three cases required split-thickness skin graft during initial surgery. One patient (Figure 2) had an ipsilateral compound fracture of the proximal tibia which required gastrocnemius flap for coverage. All patients with a range of motion less than 90 degrees [2-13] were stiff probably due to the compound nature of the fractures and this stiffness may have contributed to increased stress on the implant during joint mobilization (Table 2). In two cases $[3,8]$ in (table 2), associated ipsilateral tibia fractures may have contributed to stiffness.Case [10] (Figure 1), with locked lateral plating for periprosthetic fracture, had 0-100 degrees range of movement both before and after the medial plate augmentation.Most common fracture pattern associated with non-union was metaphyseal comminution. Intra-articular components of the fractures had healed in all cases, and non-union in the metaphyseal region contributed to the instability which was visible on varus/valgus stressing during the fluoroscopic examination.Treatment of non- 
unions following lateral locked plating is a challenging problem. In one series, only 8 out of 14 patients (57\%) achieved union during follow up, when initial locking plate was left in situ proximally, distal screws were revised and plate repositioned in 11 cases to improve reduction, and bone graft and/or bone graft substitutes were used in all cases[26]. Holzman et al attained union in 20 of the twenty-one nonunions of the distal femur by single stage addition of medial locking plate and bone graft to the original stable lateral locking plate in aseptic nonunions, and two-stage treatment in lateral plate failures treated by placement of new lateral locking plate and addition of medial locking plate and the autogenous bone graft at least two months after the first procedure[27].

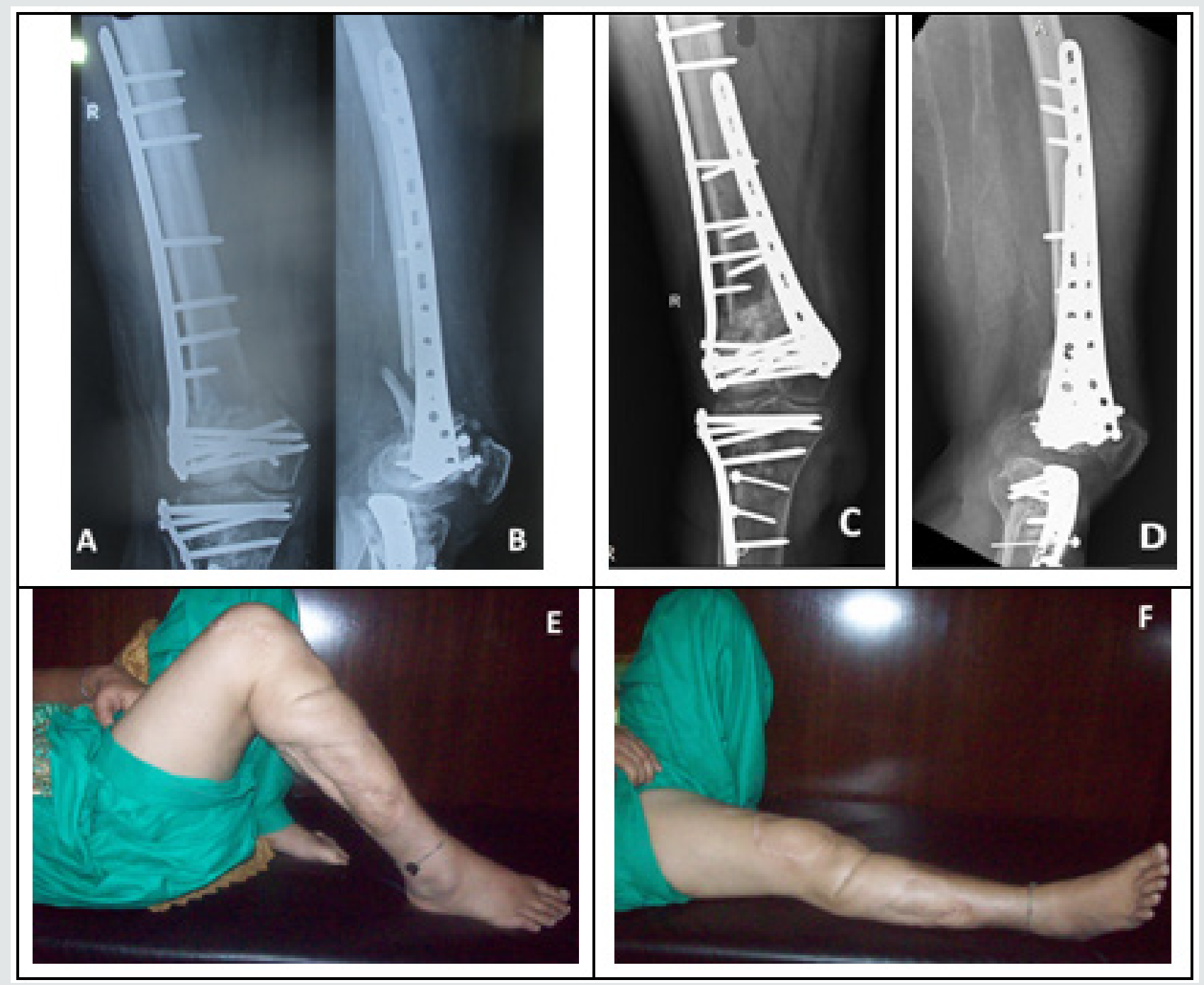

Figure 2A-F: (A and B) Anteroposterior and Lateral radiographs of 45-years-old female (case 8) showing aseptic distal femur nonunion in a compound fracture. Final followup radiographs after 30 months of surgery (C and D) showing healed nonunion and clinical photographs (E and F).

Several studies have shown that dual plating in distal femoral fractures provides increased stability by decreasing the lever arm that acts on the femoral axis and thereby decrease the load applied on the fracture[28-30]. In one latest study in which unstable distal femoral fractures created in artificial femora simulating osteoporotic bone were fixed with locked lateral plating or double plating were subjected to axial, torsional and quasi-static loading. Double plating revealed significantly smaller longitudinal and shear displacement than single lateral locked plating[31].In our series, medial plate augmentation helped to eradicate the motion at the fractures site order to eradicate which was visible before the addition of medial plate. The addition of autogenous corticocancellous bone graft from the iliac crest improved the biological environment to enhance the healing.In our series, proximal humeral locked plates were used for medial plate augmentation in 5 cases and medial distal tibia locking plates were used in 3 cases, and lateral distal femoral locking plate was applied to medial side in 4 cases, proximal tibia 'L' locking plate in one case and Low Contact 
Dynamic Compression Plate (LCDCP) in one case (Table 3). The choice of the implant was made according to the contour of the bone. Number of distal locking holes in these plates, provide more options to the surgeon while inserting the distal screws. It may not be possible to use all holes of the plate due to long screws used during locked lateral plating, which may interfere with the insertion of medial screws. No attempt was made to flush these plates with the bone to allow the bone graft to be packed between the bone and the plate. The bone graft was obtained from the posterior iliac crest. We used medial locking plates with more distal locking options, to prevent interference with long screws incorporated in the lateral locked plate.Union was achieved in all patients within 7 months, and all patients were able to put full weight on the affected lower limb once united. Range of movements of knee improved in some patients, and all patients had some pain relief.The limitations of the study are its retrospective nature, inconsistent clinical records of two patients who were not primarily treated at our hospital, a small number of patients to draw any statistically significant conclusions (Table 4). All patients treated from 2009 to 2018 could be traced and none of the patients was lost to follow up, which is the strength of our study.

Table 4: Demographic, injury, and mechanical variables.

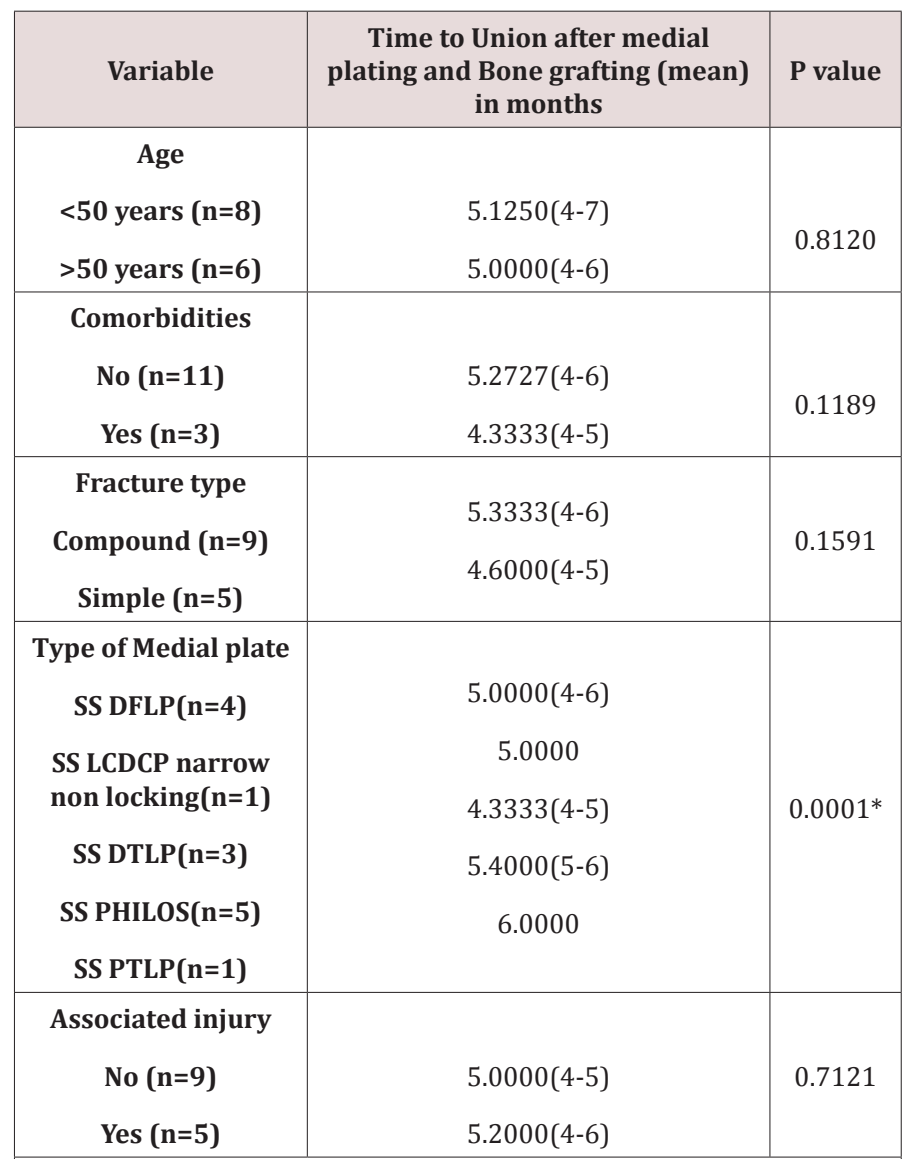

$\mathrm{SS}=$ Stainless Steel. DFLP= Distal Femur Locking Plate. $\mathrm{DTLP}=\mathrm{Distal}$ Tibia Locking Plate. PTLP= Proximal Tibia Locking Plate. PHILOS= Proximal Humerus Internal Locking System. LCDCP= Low Contact Dynamic Compression Plate.

\section{Conclusions}

Non-union of distal femoral fractures locked lateral plating have a significant influence on the quality of life of the patient. When impaired healing is evident clinico-radiologically after locked lateral plating of distal femoral fractures and the plate is stable, timely medial plating and autogenous bone grafting prevents the implant failure and leads to a successful union.

Conflicts of Interest: The authors report no conflicts of interest.

\section{Declarations of interest: None.}

Source of Funding: This research did not receive any specific grant from funding agencies in the public, commercial, or not-forprofit sectors.

\section{References}

1. Kubiak EN, Fulkerson E, Strauss E, Egol KA (2006) The evolution of locked plates. J Bone Joint Surg Am 88(Suppl 4): 189-200.

2. Gwathmey WF, Jones-Quaidoo SM, Kahler D, Hurwitz S, Cui Q et al. (2010) Distal Femoral Fractures: Current Concepts. American Academy of Orthopaedic Surgeon 18(10): 597-607.

3. Yeap E, Deepak A (2007) Distal Femoral Locking Compression Plate Fixation in Distal Femoral Fractures: Early Results. Malaysian Orthopaedic Journal 1(1): 12-17.

4. Strauss EJ, Schwarzkopf R, Kummer F, Egol KA (2008) the Current Status of Locked Plating: The Good, the Bad, and the Ugly. Journal of Orthopaedic Trauma 22(7): 479-486.

5. Vallier HA, Hennessey TA, Sontich JK, Patterson BM (2006) Failure of LCP Condylar Plate Fixation in the Distal Part of the Femur: A Report of Six Cases. The Journal of Bone \& Joint Surgery 88(4): 846-853.

6. Schütz M, Müller M, Krettek C, D Höntzsch, P Regazzoni, et al. (2001) Minimally invasive fracture stabilization of distal femoral fractures with the LISS: A prospective multicenter study results of a clinical study with special emphasis on difficult cases. Injury 32(3): 48-54.

7. Schütz M, Müller M, Regazzoni P, Dankward Höntzsch, Christian Krettek, et al. (2005) Use of the Less Invasive Stabilization System (LISS) in patients with distal femoral (A033) fractures: a prospective multicenter study. Archives of Orthopaedic and Trauma Surgery 125(2): 102-108.

8. Gaines RJ, Sanders R, Sagi JC, Haidukewych GJ (2008) Titanium versus stainless steel locked plates for distal femur fractures: is there any difference? OTA 10-13.

9. Markmiller M, Konrad G, Sudkamp N (2004) Femur-LISS and Distal Femoral Nail for Fixation of Distal Femoral Fractures. Clin Orthop Relat Res 426: 252-257.

10. Ricci WM, Loftus T, Cox C, Borrelli J (2006) Locked Plates Combined With Minimally Invasive Insertion Technique for the Treatment of Periprosthetic Supracondylar Femur Fractures Above a Total Knee Arthroplasty. Journal of Orthopaedic Trauma 20(3): 190-196.

11. Henderson CE, Lujan TJ, Kuhl LL, Bottlang M, Fitzpatrick DC, et al. (2011) 2010 Mid-America Orthopaedic Association Physician in Training Award: Healing Complications Are Common After Locked Plating for Distal Femur Fractures. Clinical Orthopaedics and Related Research $®$ 469(6):1757-1765.

12. Martinet O, Cordey J, Harder Y, Maier A, Bühler M, et al. (2000) Barraud G. the epidemiology of fractures of the distal femur. Injury Suppy 3: 6263. 
13. Zlowodzki M, Bhandari M, Marek DJ, Cole PA, Kregor PJ, et al. (2006) Operative Treatment of Acute Distal Femur Fractures: Systematic Review of 2 Comparative Studies and 45 Case Series (1989 to 2005) Journal of Orthopaedic Trauma 20(5): 366-371.

14. Perren SM (2002) Evolution of the internal fixation of long bone fractures. The scientific basis of biological internal fixation: choosing a new balance between stability and biology. J Bone Joint Surg Br. 84(8): 1093-1110.

15. Ricci WM, Streubel PN, Morshed S, Collinge CA, Nork SE, et al. (2014) Risk Factors for Failure of Locked Plate Fixation of Distal Femur Fractures. Journal of Orthopaedic Trauma 28(2): 83-89.

16. Lujan TJ, Henderson CE, Madey SM, Fitzpatrick DC, Marsh JL, et al. (2010) Locked Plating of Distal Femur Fractures Leads to Inconsistent and Asymmetric Callus Formation. Journal of Orthopaedic Trauma 24(3): 156-162.

17. Rodriguez EK, Boulton C, Weaver MJ, Lindsay M Herder, Jordan H Morgan, et al. (2014) Predictive factors of distal femoral fracture nonunion after lateral locked plating: A retrospective multicenter case-control study of 283 fractures. Injury 45(3): 554-559.

18. Rodriguez EK, Zurakowski D, Herder L, Amber Hall, Kempland C Walley, et al. (2016) Mechanical Construct Characteristics Predisposing to Nonunion After Locked Lateral Plating of Distal Femur Fractures. Journal of Orthopaedic Trauma 30(8): 403-408.

19. Linn MS, Mcandrew CM, Prusaczyk B, Brimmo O, Ricci WM, et al. (2015) Dynamic Locked Plating of Distal Femur Fractures. Journal of Orthopaedic Trauma 29(10): 447-450.

20. Pascarella R, Bettuzzi C, Bosco G, Leonetti D, Dessi S, et al. (2014) Results in treatment of distal femur fractures using polyaxial locking plate. Strategies Trauma Limb Reconstr 9(1): 13-18.

21. Hanschen M, Biberthaler P (2014) Re: Mono- versus polyaxial locking plates in distal femur fractures: a prospective randomized multicentre clinical trial. International Orthopaedics 38(8):1751-1752.

22. Tank JC, Schneider PS, Davis E, Matthew Galpin, Mark L Prasarn, et al. (2016) Early Mechanical Failures of the Synthes Variable Angle Locking Distal Femur Plate. Journal of Orthopaedic Trauma 30(1): e7-e11.
23. Chapman MW, Finkemeier CG (1999) Treatment of supracondylar nonunions of the femur with plate fixation and bone graft. J BoneJoint Surg Am 81(9): 1217-1228.

24. Gardner MJ, Toro-Arbelaez JB, Harrison M, Hierholzer C, Lorich DG, et al. (2008) Open Reduction and Internal Fixation of Distal Femoral Nonunions: Long-Term Functional Outcomes Following a Treatment Protocol. The Journal of Trauma: Injury, Infection, and Critical Care 64(2): 434-438.

25. Lynch JR, TaitsmanLA, Barei DP, Nork SE (2008) Femoral non-union: risk factors and treatment options. J Am Acad Orthop Surg 16(2): 88-97.

26. Ebraheim NA, Buchanan GS, Liu X, Maxwell E Cooper, Nicholas Peters, et al. (2016) Treatment of Distal Femur Nonunion Following Initial Fixation with a Lateral Locking Plate. Orthopaedic Surgery 8(3): 323-330.

27. Holzman MA, Hanus BD, Munz JW, O’Connor DP, Brinker MR, et al. (2016) Addition of a Medial Locking Plate to an In Situ Lateral Locking Plate Results in Healing of Distal Femoral Nonunions. Clinical Orthopaedics and Related Research® 474(6): 1498-1505.

28. Ziran BH, Rohde RH, Wharton AR (2002) Lateral and anterior plating of intra-articular distal femoral fractures treated via an anterior approach. Int Ortho 26(6): 370-373.

29. Khalil Ael S, Ayoub MA (2022) highly unstable complex C3-type distal femur fracture: can double plating via a modified Olerud extensile approach be a standby solution. J Orthop Traumatol 13(14): 179-188.

30. Steinberg EL, Elis J, Steinberg Y, Salai M, Ben-Tov T, et al. (2017) A double-plating approach to distal femur fracture: A clinical study. Injury 48(10): 2260-2265.

31. Todorov D, Zderic I, Richards RG, Mark Lenz, Matthias Knobe, et al. (2018) Is augmented LISS plating biomechanically advantageous over conventional LISS plating in unstable osteoporotic distal femoral fractures? Journal of Orthopaedic Research 36(10): 2604-2611.

32. Hoffmann MF, Jones CB, Sietsema DL, Tornetta P, Koenig SJ, et al. (2013) Clinical outcomes of locked plating of distal femoral fractures in a retrospective cohort. Journal of Orthopaedic Surgery and Research 8(1): p. 43.
This work is licensed under Creative Commons Attribution 4.0 License

To Submit Your Article Click Here:

Submit Article

DOI: $10.32474 /$ OSMOAJ.2020.04.000187

$\begin{gathered}\text { Orthopedics and Sports Medicine } \\ \text { Open Access Journal }\end{gathered}$
Assets of Publishing with us
- Global archiving of articles
- Immediate, unrestricted online access
- Rigorous Peer Review Process
- Authors Retain Copyrights
Orthopedics And Sports Medicine:
Open Access Journal

